Print ISSN: 2233-4165 / Online ISSN: 2233-5382

doi:http://dx.doi.org/10.13106/ijidb.2018.vol9.no8.27.

\title{
A Study of the Efficient Coordination of Logistic Distribution Centers for the China Project*
}

\author{
Jun-Na Jin**, Bao-Zhong Zhang***
}

Received: May 15, 2018. Revised: August 1, 2018. Accepted: August 15, 2018.

\section{Abstract}

Purpose - This paper discussed and illustrated the most efficient method to calculate the distribution centers for a national project in China. Through demonstration of implementing the GIS, spatial analysis, and location calculation model, this paper mainly dealt with the construction distribution problem and inconvenient supply of materials problems.

Research design, data, and methodology - In this paper, the research design structure based on three steps: implementing the Geographic Information System to locate the points coordination data, calculating the distribution centers of the project, and optimizing the most efficient and effective coordination. The data of the calculation is from an actual project. The methodology of this paper is summarizing the spatial analysis capabilities and digital graphic data calculation to locate logistics distribution centers, and since the illustration of the calculation is useful for locating the coordination, the result of this paper has certain reference values for the project construction.

Results - This paper illustrates the steel and cement resource of every distribution point to confirm the most efficient distribution center location coordination.

Conclusions - The integrated logistical management models are used to ensure the results for the purposes of our calculation. The result of the calculation is also a useful example for future Chinese national projects.

Keywords: ArcView, GIS, Location, Logistic, Distribution Center.

JEL Classifications: A10, R4, N5, N45.

\section{Introduction}

In the past, people often focused on transportation or warehousing when they were studying logistics distribution issues and neglected their systematic nature. Such disengagement viewpoints are often one-sided Logistics distribution system planning includes the determination of the number of distribution centers, the optimization of distribution center space layout location selection, and distribution route arrangements. This paper organically combines Geographic Information System (GIS) and the highway from Caofeidian (CFD) station to the capital city of the logistics distribution

* This study was revised and supplemented paper published at winter conference of ICBE 2017.

** First Author, Dept. of International Business and Trade, KyungHee University, Korea. E-mail: jinjunna1224@naver.com

*** Corresponding Author, Professor, Dept. of North China University of Science and Technology, China. Tel: +86-183-3276-1869, E-mail: 591952109@qq.com system planning, trying to find a fast, scientific, effective and practical planning method, focusing on the optimization of distribution center number and spatial layout of the location coordination.

\subsection{Background}

The Caofeidian(CFD) project is the largest national project in "the Eleventh Five Year Development Plan of China". The total investment of this project is 2 trillion Yuan until 2020. From the capital city of Shijiazhuang to CFD there is a highway that is $459 \mathrm{KM}$ long. The total investment of this way is 13.28 billion CNY. The project started from March of 2013 and finished in July of 2016 for 36 months.. Our research is based on this highway. In order to construct the high efficient and effective logistic distribution center we had have finished the calculation of the supply chain distribution centers before the project started. We are going to use the integrated logistical management models to ensure the calculation purpose in this paper. 


\subsection{The Advantages of GIS Introduce to Logistics Distribution}

Database technology can only solve the processing of two-dimensional table data, CAD technology can only solve the processing of pure graphics. GIS technology is combined with CAD technology and database technology and combined with management of spatial data such as distribution. In addition to the coordinate information function of the center and distribution point, it also has the functions of creating a topology and performing spatial analysis, such as a spatial database system. In the planning of this highway logistics distribution system, the location coordinates of distribution center and distribution point can be conveniently obtained through data access. in addition, the spatial analysis and topology analysis functions can be used to automatically avoid the optimization of distribution center site selection obstacle.

Using GIS, the entire distribution network with geographic background in the planning area can be intuitively displayed on the screen. Planners can easily determine the distribution centers and lines to be selected. Flexible adjustment of plans. If the planned distribution center or line is not suitable for the actual situation due to special reasons, it can be easily adjusted on the map. Visibility and interactivity. After the distribution system is planned, the user can choose to display in the form of a map while selecting different line types and colors to render the planned distribution center or line.

\section{Implementing the Geographic Information System (GIS) to Locate the Coordination.}

Modern GIS technologies use digital information, for which various digitized data creation methods are used. The most common method of data creation is digitization, where a hard copy map or survey plan is transferred into a digital medium through the use of a computer-aided design (CAD) program, and geo-referencing capabilities. With the wide availability of ortho-rectified imagery both from satellite and aerial sources, heads-up digitizing is becoming the main avenue through which geographic data is extracted. Heads-up digitizing involves the tracing of geographic data directly on top of the aerial imagery instead of by the traditional method of tracing the geographic form on a separate digitizing tablet heads-down digitizing.

\subsection{Data Representation}

GIS data represents real objects such as roads, land use, elevation, trees, waterways with digital data determining the mix. Real objects can be divided into two abstractions: discrete objects and continuous fields such as rainfall amount, or elevations. Traditionally, there are two broad methods used to store data in a GIS for both kinds of abstractions mapping references: raster images and vector. Points, lines, and polygons are the stuff of mapped location attribute references. A new hybrid method of storing data is that of identifying point clouds, which combine threedimensional points with RGB information at each point, returning a "3D color image". GIS Thematic maps then are becoming more and more realistically visually descriptive of what they set out to show or determine.

GIS data representation is suitable for the expression and management of spatial data. It not only supports variablelength records, but also supports the nesting of objects, the inheritance and aggregation of information. It allows users to define the data structure of objects and objects and its operation. It can be a spatial object. According to GIS needs, define the appropriate data structure and a set of operations.

\subsection{Spatial Analysis with GIS}

Given the vast range of spatial analysis techniques that have been developed over the past half century, any summary or review can only cover the subject to a limited depth. This is a rapidly changing field, and GIS packages are increasingly including analytical tools as standard built-in facilities or as optional toolsets, add-ins or 'analysts'. In many instances such facilities are provided by the original software suppliers commercial vendors or collaborative noncommercial development teams, whilst in other cases facilities have been developed and are provided by third parties. Furthermore, many products offer software development kits (SDKs), programming languages and language support, scripting facilities and/or special interfaces for developing one's own analytical tools or variants. The website Geospatial Analysis and associated book and e-book attempt to provide a reasonably comprehensive guide to the subject. The impact of these myriad paths to perform spatial analysis create a new dimension to business intelligence termed "spatial intelligence" which, when delivered via intranet, democratizes access to operational sorts not usually privy to this type of information.

\subsection{Slope and Aspect}

Slope, aspect and surface curvature in terrain analysis are all derived from neighborhood operations using elevation values of a cell's adjacent neighbors. Slope is a function of resolution, and the spatial resolution used to calculate slope and aspect should always be specified. The elevation at a point will have perpendicular tangents slope passing through the point, in an east-west and north-south direction. These two tangents give two components, $\partial z / \partial x$ and $\partial z / \partial y$, which then be used to determine the overall direction of slope, and the aspect of the slope. The gradient is defined as a vector quantity with components equal to the partial 
derivatives of the surface in the $\mathrm{x}$ and $\mathrm{y}$ directions.

The calculation of the overall $3 \times 3$ grid slope and aspect for methods that determine east-west and north-south component use the following formulas respectively:

$$
\begin{gathered}
\tan S=\sqrt{\left(\frac{\partial z}{\partial x}\right)^{2}+\left(\frac{\partial z}{\partial y}\right)^{2}} \\
\tan A=\left(\frac{\left(\frac{-\partial z}{\partial g}\right)}{\left(\frac{\partial z}{\partial z}\right)}\right)
\end{gathered}
$$

We describe another algorithm for calculating aspect, as follows:

$$
A=270^{\circ}+\arctan \left(\frac{\left(\frac{\partial z}{\partial z}\right)}{\left(\frac{\partial z}{\partial y}\right)}\right)-90^{\circ}\left(\frac{\left(\frac{\partial z}{\partial y}\right)}{\left|\frac{\partial z}{\partial y}\right|}\right)
$$

\subsection{Topological Modeling}

A GIS can recognize and analyze the spatial relationships that exist within digitally stored spatial data. These topological relationships allow complex spatial modeling and analysis to be performed. Topological relationships between geometric entities traditionally include adjacency what adjoins what, containment what encloses what, and proximity how close something is to something else.

\subsection{Automated Cartography}

Digital cartography and GIS both encode spatial relationships in structured formal representations. GIS is used in digital cartography modeling as a semi-automated process of making maps, so called Automated Cartography. In practice, it can be a subset of a GIS, within which it is equivalent to the stage of visualization, since in most cases not all of the GIS functionality is used. Cartographic products can be either in a digital or in a hardcopy format. Powerful analysis techniques with different data representation can produce high-quality maps within a short time period. The main problem in Automated Cartography is to use a single set of data to produce multiple products at a variety of scales, a technique known as cartographic generalization.

\section{Implementing the Project ArcView Map for Calculation}

Geographic information system (GIS) platform software has stepped into the cloud era. Arc View GIS software is easy to install, occupies less space, runs faster, and is simple to use. The ArcMap GIS software will be beneficial to users. Achieve results with half the effort. ArcView refers to the use of computer hardware and software support, the use of geographic information science and system engineering theory, scientific management and comprehensive analysis of various geographic data, to provide management, simulation, decision-making, planning, forecasting and forecasting tasks the technical systems needed for various geographic information. With the rapid development of computer technology. GIS is gradually applied to modeling and decision support in many fields, such as urban management, regional remediation and other fields.

Using GIS, the digital elevation model can be established by terrain measurement data, including terrain contour analysis, perspective analysis, slope aspect analysis, cross-sectional analysis and topographic surface area and excavation and fill volume calculation, so as to realize the road Line selection analysis to determine the best path; also can provide the required geographic information according to the user's requirements, in order to complete the work of the railway maintenance and maintenance. ArcView software is a software that can achieve the visualization of the terrain.

ArcView uses a visual graphical user interface, which is easy to operate and powerful. ArcView provides a rich feature map production function, which can efficiently query, display, and manage the attributes and data of graphics. ArcView is the most widely used desktop GIS software in the world because it provides an easy way for everyone to use geographic data. With a large array of symbols and cartographic capabilities, you can easily create high-quality maps. The ArcView software makes data management and editing a painless task that can be accomplished by anyone in your organization. Virtually any geographic data provider can make data available in ArcView software compatible format. Because data can be integrated from almost any source, projects can get started right away with data that is available locally or on the internet.

The ArcView software simplifies complex analysis and data management tasks by allowing you to visually model the task in a logical work flow. ArcView software is easy to use by nontechnical users, and advanced users will be able to take advantage of the sophisticated software tools for advanced cartography, data integration, and spatial analysis. Developers can customize ArcView software using industrystandard programming languages. ArcView is an exceptional stand-alone desktop GIS software as well as one of the core products in ArcGIS Desktop.

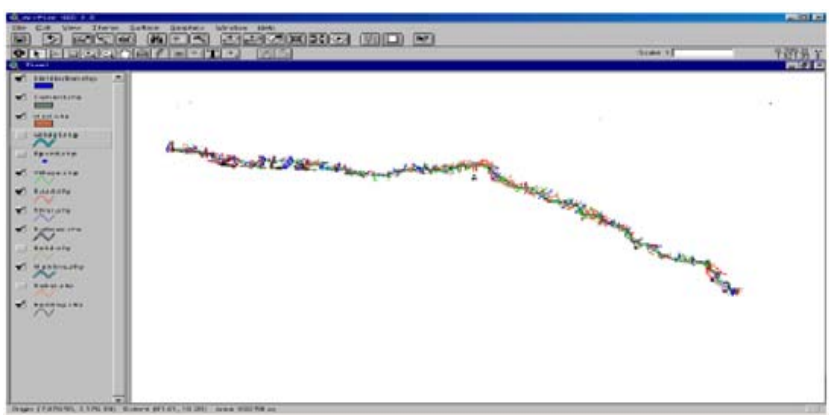

Source: The data is from the project design and research office. <Figure 1> The ArcView Map of the Project in China 
This highway project started in august in 2014, is from the capital city of Hebei province Shijiazhuang to Caofeidian in Hebei province in China, the total distance is $459 \mathrm{KM}$. We can use the GIS ArcView software to help us to confirm the geographic location data and finish our calculation. The <Figure 1> is showing the main route from Shijiazhuang to Caofeidian and the possible distribution center coordination nearby the highway.

\section{Calculating the Logistic Distribution Centers for Project in China}

The principle of location selection of regional logistics distribution centers is to ensure that logistics in protected areas is developing in a rational, green, and scientific direction. The location of regional logistics distribution centers should meet the needs of the entire region's strategic plan for economic development. Therefore, we must abide by the principle of purpose and systematic principles. The principles of coordination, economic principles, and strategic principles will lead to the correct selection of sites. The Functions of GIS describe the steps that have to be taken to implement a GIS. These steps have to be followed in order to obtain a systematic and efficient system. The steps involved are:

\subsection{Data Capture}

Data used in GIS often come from many sources. Data sources are mainly obtained from Manual Digitization and Scanning of aerial photographs, paper maps, and existing digital data sets. Remote-sensing satellite imagery and GPS are promising data input sources for GIS. In this stage Digitization is a conversion process which converts paper maps into numerical digits that can be stored in the computer. Digitizing simplifies map data into sets of points, lines, or cells that can be stored in the GIS computer is carried out. There are two basic methods of digitization: Manual Digitizing \& Scanning.

\subsection{Data Compilation}

Following the digitization of map features, the user completes the compilation phase by relating all spatial features to their respective attributes, and by cleaning up and correcting errors introduced as a result of the data conversion process. The end results of compilation is a set of digital files, each accurately representing all of the spatial and attribute data of interest contained on the original map manuscripts. These digital files contain geographic coordinates for spatial objects (points, lines, polygons, and cells) that represent mapped features.

\subsection{Data Storage (GIS Data Models)}

Once the data have been digitally compiled, digital map files in the GIS are stored on magnetic or other digital media. Data storage is based on a Generic Data Model that is used to convert map data into a digital form. The two most common types of data models are Raster and Vector. Both types are used to simplify the data shown on a map into a more basic form that can be easily and efficiently stored in the computer.

\subsection{Using the Location Model to Abstract Every Area Supply Point}

We have already got the general GIS data of the project in the third part of this paper. Let us do the calculation of distribution points. The total distance of the project is more than $450 \mathrm{KM}$, it includes more than 700 buildings. According to the local administrative area we certainly divide the whole distance into 47 items. In order to calculate the most optimized distribution center location we abstract every item as one supply point. The supply point coordination is from the calculation of the all buildings located in this item. The formula as following:

$$
x_{k}=\frac{\sum_{i=1}^{n} x_{k i} D_{k i}}{\sum_{i=1}^{n} D_{k i}}, \quad y_{k}=\frac{\sum_{i=1}^{n} y_{k i} D_{k i}}{\sum_{i=1}^{n} D_{k i}}
$$

Parameters are as following:

$x_{k}, y_{k}$ Stands for the Simplified Coordination of number $\mathrm{k}$ area.

$x_{k i}, y_{k i}$ Stands for the coordination of number $\mathrm{i}$ building in number $\mathrm{k}$ area.

$D_{k i}$ Stands for the demand amount of coordination of number $\mathrm{i}$ building in number $\mathrm{k}$ area.

Considering the resource, we need is a huge amount, so we just illustrate the steel and cement resource of every supply point need to help us confirm the distribution center location. The report of the calculation as following <Table 1>: 
$<$ Table 1> The Coordination of the Steel and Cement Supply Points

\begin{tabular}{|c|c|c|c|c|c|c|c|}
\hline & Item Name & Steel Amount & Cement & Coordination of steel supply points & \multicolumn{2}{|c|}{ Coordination of cement supply points } \\
\cline { 5 - 7 } & & & $\mathbf{X}$ & $\mathbf{Y}$ & \multicolumn{2}{|c|}{$\mathbf{X}$} & \multicolumn{2}{|c|}{$\mathbf{Y}$} \\
\hline 1 & Shuangmiao & 4915 & 24356 & 220.11 & 1646.06 & 218.49 & 1646.47 \\
\hline 2 & Fuyang & 4918 & 25674 & 466.69 & 1597.85 & 453.13 & 1607.33 \\
\hline 3 & Mangniu & 5567 & 33452 & 611.32 & 1528.98 & 602.96 & 1531.66 \\
\hline 4 & Chuhe & 3523 & 18976 & 800.26 & 1452.52 & 806.6 & 1453.76 \\
\hline 5 & Qinhe & 6451 & 35623 & 956.7 & 1432.35 & 946.47 & 1436.73 \\
\hline 6 & Minghe & 3142 & 21345 & 1184.39 & 1364.78 & 1186.27 & 1364.57 \\
\hline 7 & Mingyi & 11254 & 4562.6 & 1324.32 & 1453.8 & 1328.27 & 1440.04 \\
\hline 8 & Shagou & 4325 & 17689 & 1463.00 & 1411.61 & 1451.75 & 1409.39 \\
\hline 9 & Nansha & 12456 & 98345 & 1623.92 & 1417.02 & 1623.91 & 1417.02 \\
\hline 10 & Qili & 13421 & 56534 & 1755.4 & 1383.72 & 1754.46 & 1383.92 \\
\hline 11 & Niuwei & 3786 & 17853 & 1875.72 & 1359.6 & 1874.86 & 1359.54 \\
\hline 12 & Baima & 12546 & 65342 & 2041.37 & 1301.36 & 2041.43 & 1301.32 \\
\hline 13 & Xiaoma & 5653 & 56278 & 2247.31 & 1252.58 & 2248.52 & 1252.26 \\
\hline 14 & Liyang & 6576 & 32567 & 2394.28 & 1226.67 & 2393.54 & 1226.7 \\
\hline 15 & Dihe & 7234 & 47562 & 2632.17 & 1162.1 & 2629.35 & 1162.67 \\
\hline 16 & Wuhe & 3754 & 43258 & 2897.432 & 1163.87 & 2896.89 & 1164 \\
\hline 17 & Nanjiao & 434.43 & 1986.5 & 3035.68 & 1225.71 & 3037.78 & 1226.52 \\
\hline 18 & Zihe & 5243.24 & 26734.6 & 3099.44 & 1234.65 & 3102.86 & 1234.34 \\
\hline 19 & Huaihe & 12435.8 & 75234 & 3327.83 & 1255.28 & 3331.39 & 1255.44 \\
\hline 20 & & & $\ldots \ldots \ldots \ldots \ldots \ldots \ldots \ldots \ldots \ldots$ & & & \\
\hline
\end{tabular}

Source: The data is from the project research office.

$<$ Table 2> The location of the steel factory may be select by the project

\begin{tabular}{|c|c|l|}
\hline Factory Name & Output(Annual) & \multicolumn{1}{|c|}{ Contact } \\
\hline Beijing Shougang Group & $3,500,000$ ton & $\begin{array}{l}\text { Address: Shougang Road 114, Beijing, 100041 } \\
\text { Telephone : 010-88291114 }\end{array}$ \\
\hline Tianjin Tiangang Co. Ltd. & 750,000 ton & $\begin{array}{l}\text { Address: Jinhua Road 19, Tianjin, 301509 } \\
\text { Telephone: 022-69559722 69559799 }\end{array}$ \\
\hline Tangshan Steel Stock Co. Ltd. & 650,000 ton & $\begin{array}{l}\text { Address: Gangchang Road 11, Tangshan, 063005 } \\
\text { Telephone: 0315- 2702701 }\end{array}$ \\
\hline Handan Iron and Steel Group & 950,000 ton & $\begin{array}{l}\text { Address: Fuxing Road 232, Handan, 056000 } \\
\text { Telephone : 0310-6072141 }\end{array}$ \\
\hline Xingtai Iron and Steel Co. Ltd. & 1450,000 ton & $\begin{array}{l}\text { Address: Gangtie Nanstreet 262,Xingtai, 054027 } \\
\text { Telephone: 0319-2042022 0319-2042183 }\end{array}$ \\
\hline Shijiazhuang Steel Stock Co. Ltd. & 1000,000 ton & $\begin{array}{l}\text { Address: Heping EasternRoad 363, Shijiazhuang 050031 } \\
\text { Telephone:0311-86913910 0311-85054943 }\end{array}$ \\
\hline Xuanhua Steel Stock Co. Ltd. & 600,000 ton & $\begin{array}{l}\text { Address: Pailou Eastern Road 30, Xuanhua, 075103 } \\
\text { Telephone: 0313-8679266 0313-8679302 }\end{array}$ \\
\hline
\end{tabular}

Source: The data is from the project design and research office.

\subsection{Finding the Realistic Factory Location}

Now we can find the accurate location coordination of supply factories which supply the resource we need in our project and locate the distribution center for our project. In our project area there are some huge steel companies, the following map is showing the steel distributed network in China.

From this distributed network, we can see there are some steel factories in our project area could be selected by our project. The location of them are as following <Table 2>:

Simultaneously, we also find there are some cement factories could be selected by our project. The location of them are as following:

\subsection{The Distribution Center Location Calculation}

According to the reality, the project headquarters make the amount of distribution center scope is from 4 to 14 and budget the construction investment on each steel center is 3 million CNY and 5 million CNY on each cement center. We use the Location Selecting model to calculate the distribution centers location, the formula as following: 


$$
\begin{aligned}
& \operatorname{Min} \sum_{i=1}^{m} \sum_{j=1}^{n} z_{i} C_{i j} x_{i j}+\sum_{i=1}^{m} \sum_{k=1}^{k} z_{i} C_{i k} y_{i k}+\sum_{i=1}^{m} S_{i} z_{i} \\
& \text { S.t. }
\end{aligned}
$$

Parameters are as following:

$$
\begin{aligned}
& \int \sum_{i=1}^{m} x_{i j}=t_{j} \\
& \sum_{j=1}^{n} x_{i j}=\sum_{k=1}^{k} y_{i k} \\
& x_{i j} \geq 0 \quad i=1,2, \cdots m ; \quad j=1,2, \cdots n \\
& \left\{\begin{array}{l}
y_{i k} \geq 0 \quad k=1,2, \cdots K \\
x_{1}
\end{array}\right. \\
& \sum_{i=1}^{m} z_{i}=M
\end{aligned}
$$

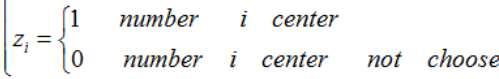

$i$ stands for the number of distribution centers

$j$ stands for the number of steel demand sites

$k$ stands for the number of steel factories

$x_{i j}$ stands for the transport amount from the

supply $i$ center to $j$ steel demand sites

$y_{i k}$ stands for the transport amount from the steel factories $k$ to the supply $i$ center

$z_{i}$ stands for number $i$ distribution center is selected $z_{i}=1$, otherwise $z_{i}=0$

$s_{i}$ stands for number $i$ distribution center construction fee

We use the unit product transportation fee formula to calculate the transport fee, the formula as following:

$$
C_{i j}=B_{i j} a_{i j} d_{i j}
$$

Parameters are as following:

$C_{i j}$ stands for from $i$ to $j$ the unit product transportation fee

$a_{i j}$ stands for from $i$ to $j$ the unit product in the unit distance transportation fee

\begin{tabular}{|c|c|c|c|c|c|c|c|c|}
\hline \multirow{2}{*}{ SC } & \multicolumn{2}{|c|}{ Coordination } & \multicolumn{2}{|r|}{ Item } & \multirow{2}{*}{$\begin{array}{l}\text { Supplied } \\
\text { Steel(ton) }\end{array}$} & \multirow{2}{*}{ Supplier Steel } & \multirow{2}{*}{$\begin{array}{l}\text { Supplied } \\
\text { Cement }\end{array}$} & \multirow{2}{*}{$\begin{array}{l}\text { Supplier } \\
\text { Cement }\end{array}$} \\
\hline & $x$ & $Y$ & \# & Item Name & & & & \\
\hline \multirow{5}{*}{1} & \multirow{5}{*}{622.4} & \multirow{5}{*}{1529.5} & 1 & Shuangmiao & 4810 & \multirow{5}{*}{$\begin{array}{c}\text { Handan Iron and Steel } \\
\text { Group }\end{array}$} & 22739 & \multirow{5}{*}{$\begin{array}{l}\text { Handan Cemen } \\
\text { Product Factory }\end{array}$} \\
\hline & & & 2 & Fuyang & 4828 & & 28129 & \\
\hline & & & 3 & Mangniu & 5890 & & 34398 & \\
\hline & & & 4 & Chuhe & 3464 & & 17968 & \\
\hline & & & 5 & Qinhe & 6389 & & 34852 & \\
\hline \multirow{6}{*}{2} & \multirow{6}{*}{1554.3} & \multirow{6}{*}{1413.7} & 6 & Minghe & 3097 & \multirow{6}{*}{$\begin{array}{l}\text { Xingtai Iron and Steel } \\
\text { CORP., Ltd. }\end{array}$} & 16364 & \multirow{6}{*}{$\begin{array}{l}\text { Xingtai Cement } \\
\text { Product Factory }\end{array}$} \\
\hline & & & 7 & Mingyi & 10318 & & 3947.58 & \\
\hline & & & 8 & Shagou & 3508 & & 18054 & \\
\hline & & & 9 & Nansha & 23219 & & 100268 & \\
\hline & & & 10 & Qili & 11063 & & 50750 & \\
\hline & & & 11 & Niuwei & 3433 & & 17395 & \\
\hline \multirow{4}{*}{3} & \multirow{4}{*}{2249} & \multirow{4}{*}{1255.9} & 12 & Baima & 11352 & \multirow{4}{*}{$\begin{array}{l}\text { Xingtai Iron and Steel } \\
\text { CORP., Ltd. }\end{array}$} & 51546 & \multirow{4}{*}{$\begin{array}{l}\text { Xingtai Cement } \\
\text { Product Factory }\end{array}$} \\
\hline & & & 13 & Xiaoma & 5798 & & 34642 & \\
\hline & & & 14 & Liyang & 6499 & & 35301 & \\
\hline & & & 15 & Dihe & 7061 & & 40610 & \\
\hline \multirow{5}{*}{4} & \multirow{5}{*}{3291.3} & \multirow{5}{*}{1236.2} & 16 & Wuhe & 3915 & \multirow{5}{*}{$\begin{array}{c}\text { Shijiazhuang Steel Stock } \\
\text { Co., Ltd. }\end{array}$} & 23712 & \multirow{5}{*}{$\begin{array}{l}\text { Shijiazhuang } \\
\text { Cement Product } \\
\text { Factory }\end{array}$} \\
\hline & & & 17 & Nanjiao & 421.27 & & 1853.35 & \\
\hline & & & 18 & Zihe & 5254.67 & & 28193.67 & \\
\hline & & & 19 & Huaihe & 16033.8 & & 71638.46 & \\
\hline & & & 20 & Beisha & 6459.9 & & 29118.89 & \\
\hline
\end{tabular}

$d_{i j}$ stands for the total distance from $i$ to $j B_{i j}$ stands for from $i$ to $j$ distance revise coefficient

After the location selecting model calculation, we can get the optimization result of the steel and cement distribution center number and every distribution center steel and cement expense. The report as following <Table 3>:

$<$ Table 3> The location of distribution center and the selected factories information 


\begin{tabular}{|c|c|c|c|c|c|c|c|c|}
\hline \multirow{2}{*}{ SC } & \multicolumn{2}{|c|}{ Coordination } & \multicolumn{2}{|r|}{ Item } & \multirow{2}{*}{$\begin{array}{l}\text { Supplied } \\
\text { Steel(ton) }\end{array}$} & \multirow{2}{*}{ Supplier Steel } & \multirow{2}{*}{$\begin{array}{l}\text { Supplied } \\
\text { Cement }\end{array}$} & \multirow{2}{*}{$\begin{array}{l}\text { Supplier } \\
\text { Cement }\end{array}$} \\
\hline & $x$ & $Y$ & $\#$ & Item Name & & & & \\
\hline \multirow{5}{*}{5} & \multirow{5}{*}{4127.6} & \multirow{5}{*}{1217.4} & 21 & Jiahe & 12480.81 & \multirow{5}{*}{$\begin{array}{l}\text { Shijiazhuang Steel Stock } \\
\text { Co., Ltd. }\end{array}$} & 53768.63 & \multirow{5}{*}{$\begin{array}{c}\text { Shijiazhuang } \\
\text { Cement Product } \\
\text { Factory }\end{array}$} \\
\hline & & & 22 & Taitou & 6480.8 & & 27627.63 & \\
\hline & & & 23 & Guyun & 6655.36 & & 23611.12 & \\
\hline & & & 24 & Yutuo & 21960.28 & & 128107.06 & \\
\hline & & & 25 & Yongan & 1230.82 & & 6159.88 & \\
\hline \multirow{5}{*}{6} & \multirow{5}{*}{4958.3} & \multirow{5}{*}{686.7} & 26 & Xian & 761.78 & \multirow{5}{*}{$\begin{array}{c}\text { Shijiazhuang Steel Stock } \\
\text { Co., Ltd. }\end{array}$} & 3683.43 & \multirow{5}{*}{$\begin{array}{l}\text { Shijiazhuang } \\
\text { Cement Product } \\
\text { Factory }\end{array}$} \\
\hline & & & 27 & Cihe & 7832.5 & & 34339.2 & \\
\hline & & & 28 & Shabei & 19301.21 & & 74379.44 & \\
\hline & & & 29 & mengliang & 8009.58 & & 38023.83 & \\
\hline & & & 30 & Tang & 7135.79 & & 32937.14 & \\
\hline \multirow{5}{*}{7} & \multirow{5}{*}{5838.7} & \multirow{5}{*}{81.1} & 31 & Lijia & 3695.49 & \multirow{5}{*}{$\begin{array}{c}\text { Shijiazhuang Steel Stock } \\
\text { Co., Ltd }\end{array}$} & 19566.39 & \multirow{5}{*}{$\begin{array}{l}\text { Shijiazhuang } \\
\text { Cement Product } \\
\text { Factory }\end{array}$} \\
\hline & & & 32 & Fangshui & 5629.94 & & 25725.94 & \\
\hline & & & 33 & Quni & 4128.51 & & 18666.11 & \\
\hline & & & 34 & Puyang & 4888.72 & & 24801.29 & \\
\hline & & & 35 & Wushan & 7762.57 & & 39552.37 & \\
\hline \multirow{6}{*}{8} & \multirow{6}{*}{$\begin{array}{c}6295 . \\
5\end{array}$} & \multirow{6}{*}{-309.4} & 36 & Wuzhuang & 5958.5 & \multirow{6}{*}{$\begin{array}{c}\text { Xuanhua Steel Stock Co., } \\
\text { Ltd. }\end{array}$} & 36349.54 & \multirow{6}{*}{$\begin{array}{c}\text { Baoding } \\
\text { Cement Product } \\
\text { Factory }\end{array}$} \\
\hline & & & 37 & Caohe & 14664 & & 62932 & \\
\hline & & & 38 & Gangtou & 4708.4 & & 34085.37 & \\
\hline & & & 39 & Liuzhuang & 3766.96 & & 19593.37 & \\
\hline & & & 40 & Fushan & 9235.49 & & 47599.52 & \\
\hline & & & 41 & Baohe & 5590.73 & & 25217.38 & \\
\hline \multirow{6}{*}{9} & \multirow{6}{*}{6997.1} & \multirow{6}{*}{-779.6} & 42 & Zhongyi & 4952.14 & & 28490.87 & \\
\hline & & & 43 & Beiyi & 6617.93 & & 25701.91 & \\
\hline & & & 44 & Fenzhuang & 2160.59 & Poiting chougne Croun & 10520.61 & Baoding \\
\hline & & & 45 & Xiache & 4392.19 & BelJing Shougang Group & 19744.71 & Cement Product \\
\hline & & & 46 & Nanju & 6271.29 & & 31330.73 & \\
\hline & & & 47 & Beiju & 4386.11 & & 22621.52 & \\
\hline
\end{tabular}

After the calculation we can see the geographic coordination of every distribution center, we can make sure which area the distribution centers located in. The results are shown in $<$ Table $4>$

$<$ Table 4> The locations of the distribution centers

\begin{tabular}{|c|c|}
\hline Distribution center & Location of the center \\
\hline 1 & Handan \\
\hline 2 & Shahe \\
\hline 3 & Neiqiu \\
\hline 4 & Yuanshi \\
\hline 5 & Shijiazhuang \\
\hline 6 & Zhengding \\
\hline 7 & Xinle \\
\hline 8 & Baoding \\
\hline 9 & Zhuozhou \\
\hline
\end{tabular}

Throughout the calculation above, we can see the result of the best location for the logistic distribution center for the project. Considering the resource, we need a huge amount of kinds of materials for the project, so we just illustrate the steel and cement resource of every supply point need to help us confirm the distribution center location. And also, one project need more than thousands of materials, the calculation is same with the calculation in the steel and cement logistic distribution center.

\section{Conclusion}

This case for the total distance of the project is longer than $450 \mathrm{KMs}$ and the project managers divided it into 47 items. In the supply point calculation the project managers use the formula to calculate 47 supply points of each item. Throughout the calculation, we can see the result of the best location for the logistic distribution center for the project.

Today the GIS is the most popular program for choosing distribution centers. The project managers use the GIS data of the project to find the location coordination of supply centers. Then accurate locations of supply factories supplying resources and locations of distribution centers for the project are found. Actually, the project headquarters estimates the number of distribution centers from 4 to 14 and the budget of the construction investment on each steel center is 3 million RMB and 5 million RMB for the cement center. The Location Selecting model is used to analyze the 
distribution center location.

After the location selecting analysis, an optimal number of steel and cement distribution centers and the expenses of each distribution center for steel and cement are found. After the analysis, the geographic coordination of distribution centers is also made so that the project managers can make sure which specific area the distribution centers are to be located. In reality with more complex situations, according to the above findings large engineering project managers may use the experience and skills which we have summarized from the highway project of this paper. Those experiences and skills can be applied to optimize and design the materials supply chain distribution centers for other national construction projects. Also, integrated logistical management models and calculation skills concluded by this paper may be used to ensure other successful national construction projects.

\section{References}

Ailawadi, K. L., Zhang, J., Krishna, A., \& Kruger, M. W. (2010). When Wal-Mart Enters: How Incumbent Retailers React and How This Affects Their Sales Outcomes. Journal of Marketing Research, 47(4), 577-593.

An, L., Choi, N. H., \& Lim, A. Y. (2013). The Roles of Economic Benefits and Identity Salience: Inducing Factors in the Behavioral Intent to Use Outlet Shopping Centers. Journal of Distribution Science, 11(6), 41-50.

Bansal, V. K., \& Pal, M. (2009). Extended GIS for Construction Engineering by Adding Direct Sunlight Visualizations on Buildings. Construction Innovation, 9(4), 406-419.

Barratt, M. (2004). Understanding the Meaning of Collaboration in the Supply Chain. Supply Chain Management: An International Journal, 9(1), 30-42.

Bloch, P. H., \& Richins, M. L. (1983), Shopping Without Purchase: An Investigation of Consumer Browsing Behavior. Advances in Consumer Research, 10, 389-393.

Cassivi, L. (2006). Collaboration Planning in a Supply Chain. Supply Chain Management: An International Journal, 11(3), 249-258.

Cox, A. (1999). Power, Value and Supply Chain Management. Supply Chain Management: An International Journal, 4(4), 167-175.

Fatemi, A., \& Glaum, M. (2000). Risk Management Practices of German Firms. Managerial Finance, 26(3), 1-17.
Fraser, I., \& Henry, W. (2007). Embedding Risk Management: Structures and Approaches. Managerial Auditing Journal, 22(4), 392-409.

Galloway, D., \& Funston, R. (2000). The Challenges of Enterprise Risk Management. Balance Sheet, 8(6), 22-25.

Garofoli, G. (2002). Local Development in Europe: Theoretical models and international comparisons. European Urban and Regional Studies, 9(3), 225-239.

Hoole, R. (2005). Five Ways to Simplify Your Supply Chain. Supply Chain Management: An International Journal, 10(1), 3-6.

Jüttner, U., \& Maklan, S. (2011). Supply Chain Resilience in the Global Financial Crisis: An Empirical Study. Supply Chain Management, 16(4), 246-259.

Kim, K. C. (2009). A Study on Improving Scheme and An Investigation into the Actual Condition about Components of Physical Distribution System. Journal of Distribution Science, 7(4), 47-56.

Marco, A. D., \& Mangano, G. (2011). Relationship between Logistic Service and Maintenance Costs of Warehouses. Facilities, 29(9/10), 411-421.

New, S. J. (2007). The Scope of Supply Chain Management Research. Supply Chain Management: An International Journal, 2(1), 15-22.

Oloruntoba, R., \& Gray, R. (2006). Humanitarian Aid: An Agile Supply Chain?. Supply Chain Management: An International Journal, 11(2), 115-120.

Park, J. S., \& Kwon, M. K. (2016). A study of Kosa Mart Re-design for the Development of Nadle Stores. Journal of Distribution Science, 14(10), 153-164.

Prasanta, K., Dey, S., \& Ogunlana, O. (2004). Selection and Application of Risk Management Tools and Techniques for Build-Operate-Transfer Projects. Industrial Management and Data Systems, 104(4), 334-346.

So, J. H., \& Hwang, H. J. (2012). A Study on the Locational Decision Factors of Discount Stores: The Case of Cheonan. Journal of Distribution Science, 10(5), 37-43.

Shuai Su (2013). A study of Chinese distribution policies and challenges. The International Journal of Industrial Distribution \& Business, 4(1), 11-14.

Shuai Su (2013). Study of Chinese Distribution Market Trends. Journal of Distribution Science, 11(9), 31-34. 